Article

\title{
Assessment of Runoff Components Simulated by GLDAS against UNH-GRDC Dataset at Global and Hemispheric Scales
}

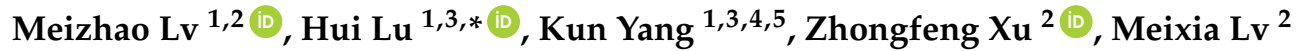 \\ and Xiaomeng Huang 1,3 \\ 1 Ministry of Education Key Laboratory for Earth System Modeling, Department of Earth System Science, \\ Tsinghua University, Beijing 100084, China; meizhao2864@163.com (M.L.); yangk@tsinghua.edu.cn (K.Y.); \\ hxm@tsinghua.edu.cn (X.H.) \\ 2 CAS Key Laboratory of Regional Climate-Environment for Temperate East Asia, Institute of Atmospheric \\ Physics, Chinese Academy of Sciences, Beijing 100029, China; xuzhf@tea.ac.cn (Z.X.); \\ meixialv22@gmail.com (M.L.) \\ 3 Joint Center for Global Change Studies, Beijing 100875, China \\ 4 CAS Center for Excellence in Tibetan Plateau Earth System, Beijing 100101, China \\ 5 Key Laboratory of Tibetan Environment Changes and Land Surface Processes, Institute of Tibetan Plateau \\ Research, Chinese Academy of Sciences, Beijing 100101, China \\ * Correspondence: luhui@tsinghua.edu.cn
}

Received: 13 June 2018; Accepted: 23 July 2018; Published: 24 July 2018

\begin{abstract}
The current evaluations of global land data assimilation system (GLDAS) runoff were generally limited to the observation-rich areas. At the global and hemispheric scales, we assessed different runoff components performance of GLDAS (1.0 and 2.1) using the University of New Hampshire and Global Runoff Data Centre (UNH-GRDC) dataset. The results suggest that GLDAS simulations show considerable uncertainties, particularly in partition of surface and subsurface runoffs, in snowmelt runoff modeling, and in capturing the northern peak time. GLDAS1.0-CLM (common land model) produced more surface runoff almost globally; GLDAS-Noah generated more surface runoff over the northern middle-high latitudes and more subsurface runoff in the remaining areas; while the partition in GLDAS1.0-VIC (variable infiltration capacity) is almost opposite to that in Noah. Comparing to GLDAS1.0-Noah, GLDAS2.1-Noah improved the premature snow-melting tendency, but its snowmelt-runoff peak magnitude was excessively high in June and July. The discrepancies in northern primary peak times among precipitation and runoff is partly caused by the combination of rainfall and melting-snow over high-latitude, as well as the very different temporal-spatial distributions for snowmelt runoff simulated by GLDAS models. This paper can provide valuable guidance for GLDAS users, and contribute to the further improvement of hydrological parameterized schemes.
\end{abstract}

Keywords: runoff component simulation; peak time; snowmelt; global and hemispheric scales; GLDAS

\section{Introduction}

Hydrological processes play an important role in land-atmosphere interactions at different temporal and spatial scales (basin, region, and globe) [1-4]. Kuhl and Miller [5] pointed out "a model's ability to simulate monthly river runoff is a good test of its hydrologic cycle and surface parameterizations in different climatic regions and provides a useful diagnostic for climate modelers". Increasingly, evidence indicates that without a better description of hydrology, climate change 
prediction cannot be improved [6-9]. The global land data assimilation system (GLDAS) is an important data source for hydrological research. The GLDAS provides optimal fields of land surface states and fluxes by integrating a huge quantity of satellite- and ground-based observational data products, using advanced land surface modeling and data assimilation techniques [10,11]. The GLDAS data have been widely used [12-18], such as in land-atmosphere interaction study (e.g., [19]), initialization of climate modeling (e.g., [20]), evaluation and interpretation of GRACE satellite data (e.g., [15]), and snowmelt study (e.g., [21]).

A quantitative evaluation of the GLDAS results is critical for its application. However, the evaluations of GLDAS results have usually been limited to America (e.g., [22,23]), China (e.g., [16,24,25]), and other observation-rich regions [18,26], although its one strength is to provide information in data-poor areas $[13,27]$. To our knowledge, only a few GLDAS evaluations have been conducted at the global scale. For example, Jiménez et al. [28] carried out a global intercomparison of GLDAS heat flux estimates. Ferguson et al. [29] showed that, of the GLDAS models, the global surface soil moistures from the common land model (CLM) and Noah were simulated better than Mosaic and variable infiltration capacity (VIC). Runoff is also an important component of the water cycle and is closely related to, and affects, other components of the water cycle. In some studies, GLDAS runoff has been evaluated indirectly by comparing a GLDAS-driven river routing model simulation with observed streamflows. For example, Zaitchik et al. [18] introduced a water routing scheme to the runoff results of GLDAS in 66 main basins throughout the world. Their results suggested that the four models in GLDAS yielded substantially different estimates of river discharge and regional disparities. In a study by Bai et al. [12], the streamflows simulated by models in GLDAS coupled with a river routing model were evaluated against observed streamflows in five river basins on the Tibetan Plateau. Their study showed that CLM and Noah overestimated the runoff, whereas VIC and Mosaic underestimated it. They also found that Noah presented the best performance in capturing the seasonal cycle of runoff. However, the application of a water routing module is likely to introduce uncertainty to the river discharge results. Moreover, even if the total runoff is correctly simulated, it does not necessarily suggest that the values of surface and subsurface components are reasonable too. The partition of total runoff into surface and subsurface runoffs can significantly affect soil moisture, groundwater, and evapotranspiration. To our knowledge, the performance of GLDAS in simulating different runoff components is seldom assessed, especially at the global scale.

In this study, we assessed the runoff simulated by two versions of GLDAS against the University of New Hampshire and Global Runoff Data Centre (UNH-GRDC) composite runoff dataset. The assessment focuses on the temporal and spatial distributions at global and hemispheric scales. In addition, the surface and subsurface runoff components are also compared between different GLDAS models. The results of this study can guide GLDAS users to select the proper model results in global and hemispheric scale studies, as well as benefit the further improvement of land surface hydrological models.

\section{Materials and Methods}

\subsection{GLDAS}

GLDAS drives multiple offline (not coupled to the atmosphere) land surface models, integrates a huge quantity of observation-based data, and executes globally at high resolutions (2.5 to $1 \mathrm{~km})$, enabled by the Land Information System [10]. The data were acquired as part of the mission of NASA's Earth Science Division and archived and distributed by the Goddard Earth Sciences (GES) Data and Information Services Center (DISC). The temporal resolution for the GLDAS product is up to three hours, and the monthly products are generated through temporal averaging of the three-hourly products. Until now, there have been two versions of GLDAS (GLDAS-1, GLDAS-2). The GLDAS-1 product covers the period 1 January 1979 to present, and is forced by a combination of model data and observational data. Recently, Rui and Beaudoing [30] found high uncertainty in the GLDAS-1 
forcing fields during the period of 1995-1997. GLDAS-2 includes two versions, GLDAS-2.0 and GLDAS-2.1. The main objective for GLDAS-2.0 is to create more climatologically consistent data sets, using the Global Meteorological Forcing Dataset from Princeton University, covering from 1948 to 2010. GLDAS-2.1 is analogous to the GLDAS-1 product stream, forced with a combination of National Oceanic and Atmospheric Administration (NOAA)/Global Data Assimilation System (GDAS) atmospheric analysis fields [31], the disaggregated Global Precipitation Climatology Project (GPCP) precipitation fields [32], and the Air Force Weather Agency's Agricultural Meteorology modeling system (AGRMET) radiation fields. GLDAS-2.1 covers the period 1 January 2000 to present. Currently, only the output from the Noah model is available for GLDAS-2.1. There are four main differences between GLDAS-1 and GLDAS-2.1. Firstly, GLDAS-2.1 corrected the AGRMET and GDAS radiation, and used the combination of GPCP and GDAS precipitation; secondly, the Noah model version was upgraded; thirdly, the MODIS based land surface parameters are used in the current GLDAS-2.1 products, while the AVHRR based parameters were used in GLDAS-1; finally, an enhancement included the initialization of soil moisture over desert.

Table 1. GLDAS models' schemes.

\begin{tabular}{|c|c|c|c|}
\hline Model Version & Origin & Soil Layers & Features \\
\hline GLDAS1.0-VIC4.04 & $\begin{array}{l}\text { 1. It was developed at the } \\
\text { University of Washington and } \\
\text { Princeton University; } \\
\text { 2. It is a macroscale, } \\
\text { semi-distributed, grid-based, } \\
\text { hydrologic model. }\end{array}$ & $\begin{array}{c}3 \text { layers: } \\
0-0.1, \\
0.1-1.6 \\
1.6-1.9 \mathrm{~m}\end{array}$ & $\begin{array}{l}\text { 1. Sub-grid heterogeneity based } \\
\text { on the Xin'anjiang Hydrology } \\
\text { Model [36]; } \\
\text { 2. It was run in the water budget } \\
\text { mode in GLDAS-1; } \\
\text { 3. It has a snowpack module; } \\
\text { 4. No groundwater/glacier/ice } \\
\text { sheet/human activity modules; } \\
\text { 5. One dimension. }\end{array}$ \\
\hline $\begin{array}{l}\text { GLDAS1.0-Noah2.7 } \\
\text { GLDAS2.1-Noah3.3 }\end{array}$ & $\begin{array}{l}\text { 1. It was borne under the } \\
\text { background of developing a LSM } \\
\text { to be used for operations and } \\
\text { research in NCEP weather and } \\
\text { climate prediction models and } \\
\text { their data assimilation systems. }\end{array}$ & $\begin{array}{c}4 \text { layers: } \\
0 .-0.1 \\
0.1-0.4 \\
0.4-1.0 \\
1.0-2.0 \mathrm{~m}\end{array}$ & $\begin{array}{l}\text { 1. It has been used operationally } \\
\text { in NCEP models since 1996; } \\
\text { 2. It has a snowpack module; } \\
\text { 3. No groundwater/glacier/ice } \\
\text { sheet/human activity modules; } \\
\text { 4. One dimension. }\end{array}$ \\
\hline
\end{tabular}

CLM, VIC, Noah in GLDAS-1.0 and Noah in GLDAS-2.1 have been used in this study. The key features of these land surface models are summarized in Table 1. The forcing data is one of the main sources of uncertainties in the GLDAS result. As mentioned above, highly uncertain forcing fields existed in 1995-1997 [30]. Zhou et al. [37] also pointed out that the GLDAS1.0-1996 precipitation data were not reliable for land-surface flux simulations. Wang et al. [16] showed that GLDAS1.0 had serous discontinuity issues in its forcing data over China, with large temperature errors during 2000-2005. In view of these issues, the analysis period in this study was selected as the most recent 10 years after 2006. Given the unreliable forcing data in Greenland and the lack of a glacier/ice sheet model, we excluded the Greenland area in this study. 


\subsection{UNH-GRDC}

In order to evaluate the accuracy of modeled runoff, it is essential to compare it with observations. The University of New Hampshire and Global Runoff Data Centre (UNH-GRDC) Composite Runoff Dataset V1.0 is recognized as the only, and best, available gridded runoff dataset for the global evaluation of land surface models [38,39], and includes the annual and monthly climatological global runoff fields. The UNH-GRDC is a gridded runoff dataset at 0.5 degree resolution. This dataset was obtained by combining the observed river discharge information from the Global Runoff Data Centre with a climate-driven Water Balance Model (WBM) developed by the UNH. This observed river discharge information from the Global Runoff Data Centre is a unique collection of river discharge data collected at daily or monthly intervals from more than 9000 stations in 160 countries. Such gridded climatological runoff composite fields preserve the accuracy of the discharge measurements as well as the spatial and temporal distribution of simulated runoff, thereby providing the "best estimate" of terrestrial runoff over large domains $[40,41]$.

\subsection{Statistical Metrics}

The GLDAS runoff performances were validated against UNH-GRDC composite runoff dataset by the statistical indexes of the area-weighted average, pattern correlation coefficient (PCC), uncentered root-mean-square error (RMSE), relative bias (RB), and ratio of the standardized deviation (RSD). The metrics equations are defined as

$$
\begin{gathered}
R B=\frac{\sum_{i=1}^{N} x_{i}}{\sum_{i}^{N} y_{i}}-1 \\
R S D=\sqrt{\sum_{i=1}^{N}\left(x_{i}-\bar{x}\right)^{2} / \sum_{i=1}^{N}\left(y_{i}-\bar{y}\right)^{2}} \\
P C C=\frac{\sum_{i=1}^{N}\left(x_{i}-\bar{x}\right)\left(y_{i}-\bar{y}\right)}{\sqrt{\sum_{i=1}^{N}\left(x_{i}-\bar{x}\right)^{2} \sum_{i=1}^{N}\left(y_{i}-y\right)^{2}}} \\
R M S E=\sqrt{\frac{\sum_{i=1}^{N}\left(x_{i}-y_{i}\right)^{2}}{N}}
\end{gathered}
$$

where $x_{i}$ is the simulated data set and $\bar{x}$ is the average value for the simulation; $y_{i}$ is the observed data set and $\bar{y}$ is the average for the observation; $N$ is the number of data points in the comparison. These metrics were computed globally for each model except for Greenland. Before computing the metrics, CLDAS data was regridded to $0.5^{\circ} \times 0.5^{\circ}$ resolution to be consistent with the UNH-GRDC data sets using bilinear interpolation. Moreover, Taylor diagrams [42] were also used to summarize multiple statistics between annual GLDAS and UNH-GRDC runoff data. 


\section{Results and Discussion}

\subsection{Evaluation of Total Runoff}

Overall, the total runoff modeled by GLDAS exhibited reasonable spatial distribution, but with large magnitude disparity and peak time difference (particularly in snow melt regions). The runoff from GLDAS1.0-CLM and GLDAS2.1-Noah was close to UNH-GRDC, and GLDAS2.1-Noah performed the best in statistics. GLDAS1.0-Noah and GLDAS1.0-VIC obviously underestimated the runoff. Meanwhile, all of GLDAS models underestimated the runoff in the north of South America and south-southeast Asia (Figure 1). This result was consistent with an earlier study where in 66 basins across the globe, GLDAS1.0-CLM yielded the highest runoff while GLDAS1.0-Noah and GLDAS1.0-VIC had a tendency to underestimate the runoff [18]. The performance of GLDAS in producing annual total runoff in different regions is summarized in the Taylor diagram (Figure 2). The pattern correlation coefficients ranged from 0.6 to 0.8 . The normalized standard deviations were only 0.25 to 0.6 suggesting that all models clearly underestimated the spatial variance of runoff. At global and hemispheric scales, the performance of the four models was close to each other. GLDAS data generally show a larger bias in the northern high-latitude areas than in other areas. However, the bias was relatively smaller in Africa. In northern high-latitude areas and Africa, GLDAS2.1-Noah performed moderately better than did the other three models (Figure 2).

To assess the seasonal variations in spatial simulation capabilities, we computed metrics of the pattern correlation coefficient (PCC), uncentered root-mean-square error (RMSE), relative bias (RB), and ratio of the standardized deviation (RSD) using spatial data field for each month (Figure 3). We can see that the PCC was higher for GLDAS2.1-Noah than the other models throughout the year. The PCC values in GLDAS2.1-Noah were higher than 0.6, whereas GLDAS1.0 models showed a relatively smaller PCC. In terms of the RB, the models all showed a negative bias. However, the RB in GLDAS2.1-Noah and GLDAS1.0-CLM are clearly smaller than GLDAS1.0-Noah and GLDAS1.0-VIC. The changes in the RSD were relatively small from month to month. GLDAS2.1-Noah performed better in simulating the spatial variance of runoff than the other models although all the models underestimated RSD. The RMSE curves from GLDAS1.0 presented very slight differences, and the GLDAS2.1-Noah showed a lower RMSE than other models, especially from May to July. It should be noted that all GLDAS datasets show a worse performance around June characterized by a lower PCC, and greater RB and RMSE. 
GLDAS1.0-CLM

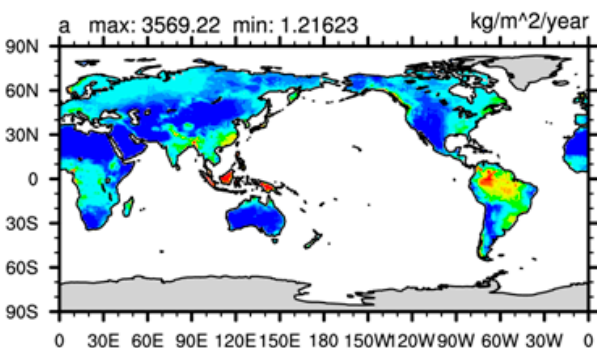

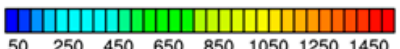

GLDAS1.0-VIC

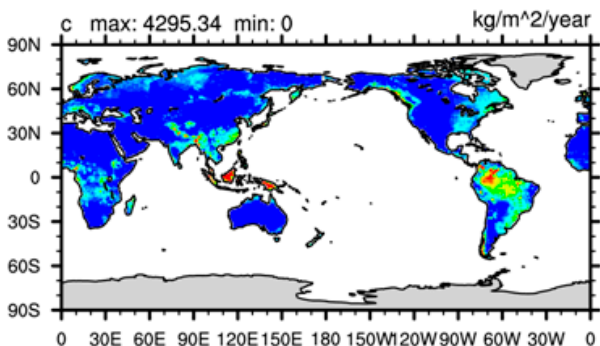

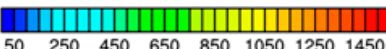

GLDAS1.0-Noah

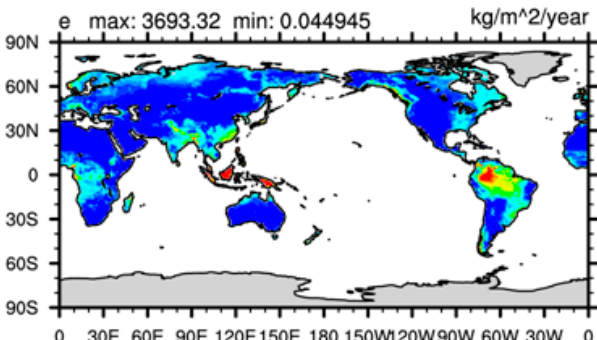

एШ

GLDAS2.1-Noah

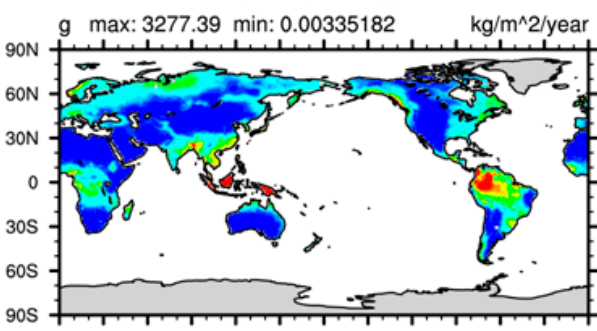

o 30E 6OE 90E 120E150E 180 150WI20W90W 6OW 30W 0

UNH-GRDC minus GLDAS1.0-CLM
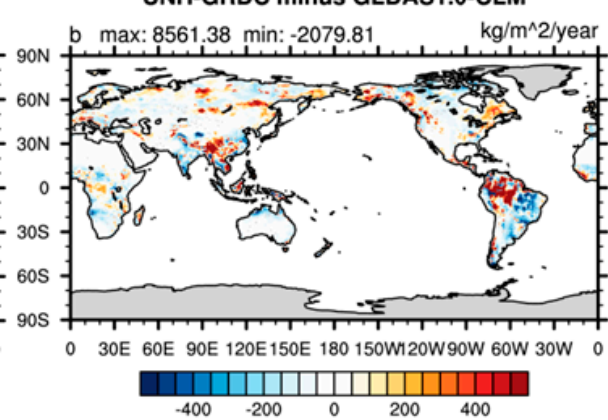

UNH-GRDC minus GLDAS1.0-VIC

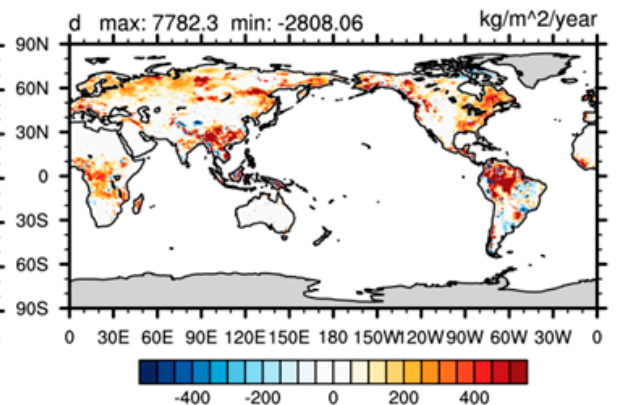

UNH-GRDC minus GLDAS1.0-Noah

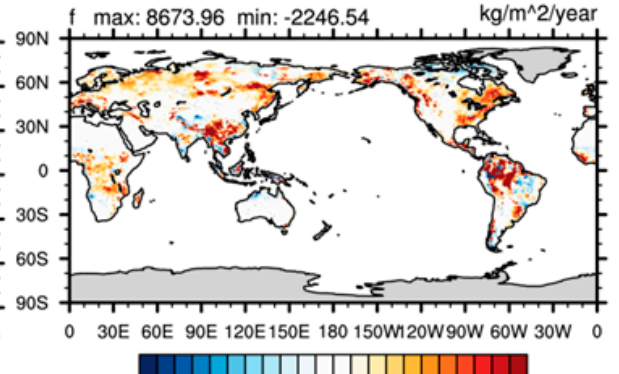

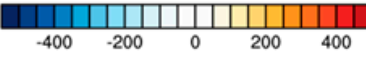

UNH-GRDC minus GLDAS2.1-Noah

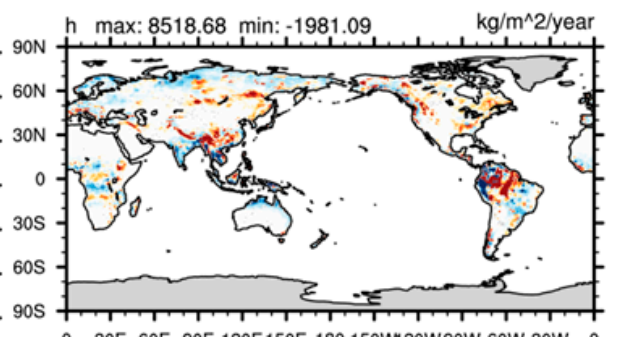

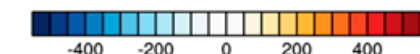

UNH-GRDC

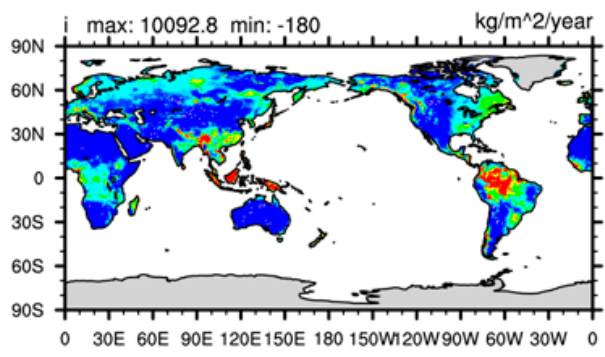

$\begin{array}{lllllllll}50 & 250 & 450 & 650 & 850 & 1050 & 1250 & 1450\end{array}$

Figure 1. The annual mean total runoff and differences between GLDAS and UNH-GRDC. 


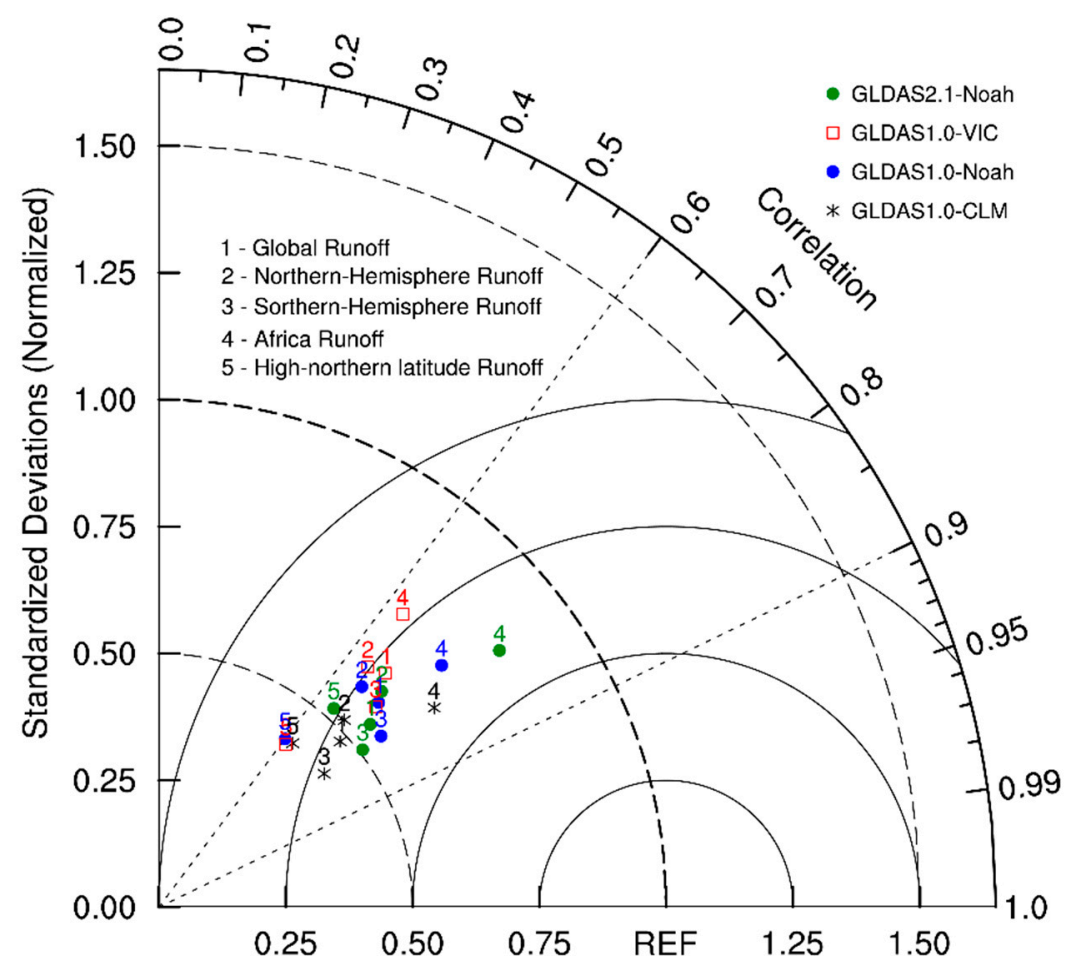

Figure 2. Taylor diagrams of annual mean total runoff for GLDAS2.1-Noah (green dot), GLDAS1.0-VIC (red square), GLDAS1.0-Noah (blue dot), and GLDAS1.0-CLM (black star).
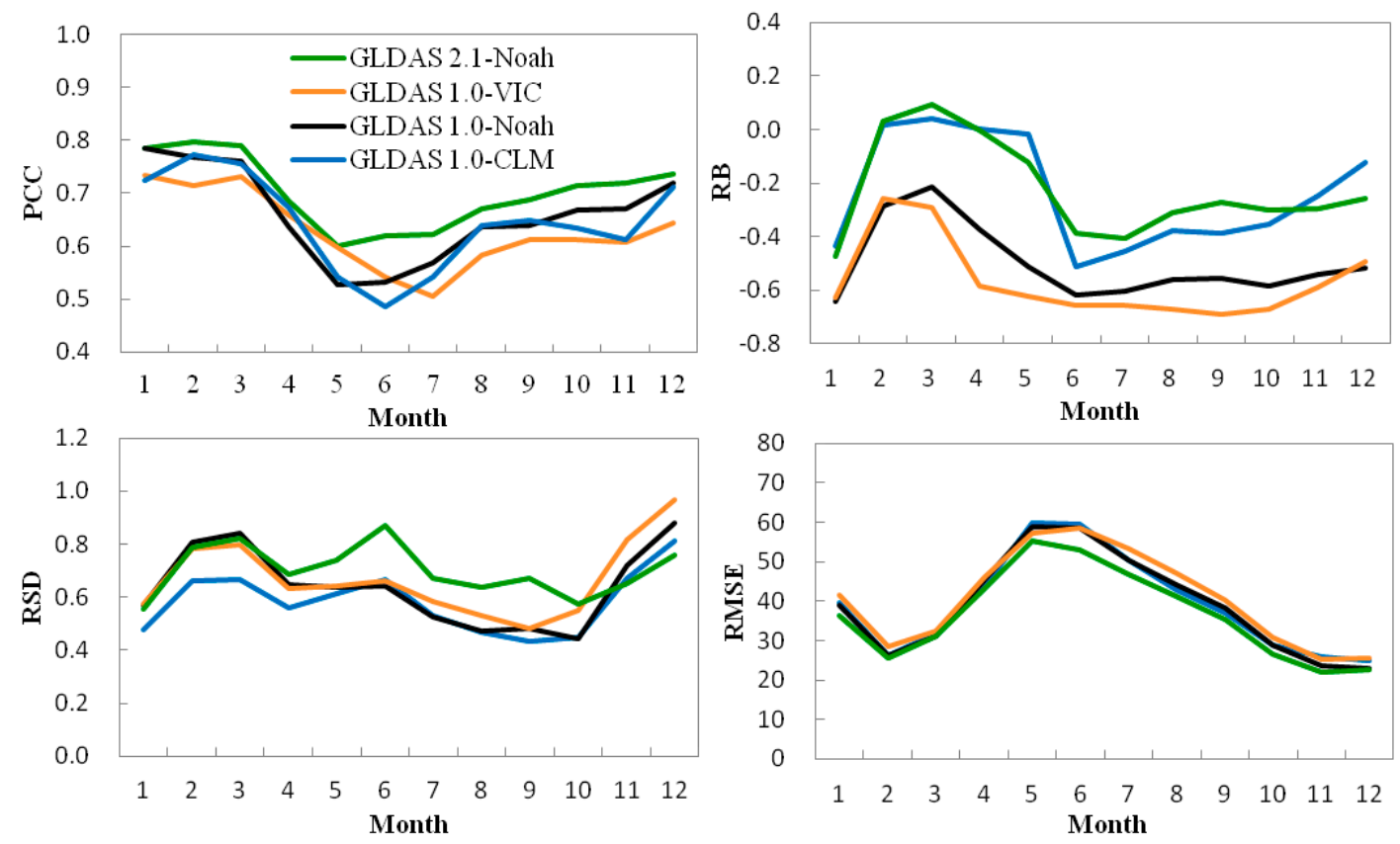

Figure 3. Pattern correlation coefficient (PCC), uncentered root-mean-square error (RMSE), relative bias (RB), and ratio of the standardized deviation (RSD) of total runoff. The statistics are computed based on global runoff derived from each of four GLDAS datasets and UNH-GRDC.

The disparities in monthly change tendency were very apparent among GLDAS models and UNH-GRDC (Figure 4). In terms of magnitude of runoff peak, it again clearly showed that GLDAS1.0-VIC and GLDAS1.0-Noah underestimated the total runoff, especially over the northern hemisphere. On a global scale, UNH-GRDC runoff showed two peaks in January and June, which corresponded to a month 
of maximum runoff in the southern and northern hemispheres, respectively. Although the GLDAS models also exhibited two peaks, these peak times were clearly different from those in UNH-GRDC. The peak times were May and August for GLDAS1.0-CLM, March and May for GLDAS1.0-VIC, and April and September for GLDAS1.0-Noah and GLDAS2.1-Noah. In the northern hemisphere, none of the GLDAS models presented the January peak flow in the same way as the UNH-GRDC. GLDAS1.0-VIC showed a single peak, with June as the peak time, while the others showed two peaks in May and August. In the southern hemisphere, only GLDAS1.0-CLM had two peaks as just the same time as UNH-GRDC. Using a water routing scheme in 66 basins throughout the globe, Zaitchik et al. [18] stated that GLDAS1.0-VIC was generally quite accurate in estimating the timing of peak discharge globally. In this study, we found GLDAS1.0-VIC only exhibited an accurate peak time for the northern hemisphere. Seen from the RMSE for the monthly area-weighted average runoff in Table 2, GLDAS2.1-Noah exhibited the best intra-annual variations at the global and hemispheric scales, then followed by GLDAS1.0-CLM. This result was different to earlier intercomparisons $[12,18]$ which indicated that among GLDAS1.0 models, GLDAS1.0-Noah presented the best performance in simulating the seasonal cycle. It should be noted that the earlier intercomparisons were conducted on a basin scale, using a water routing module, which may account for the difference from our results. Moreover, in the southern hemisphere, GLDAS1.0-CLM overestimated the runoff in November and December, and GLDAS2.1-Noah obviously overestimated the runoff in March.
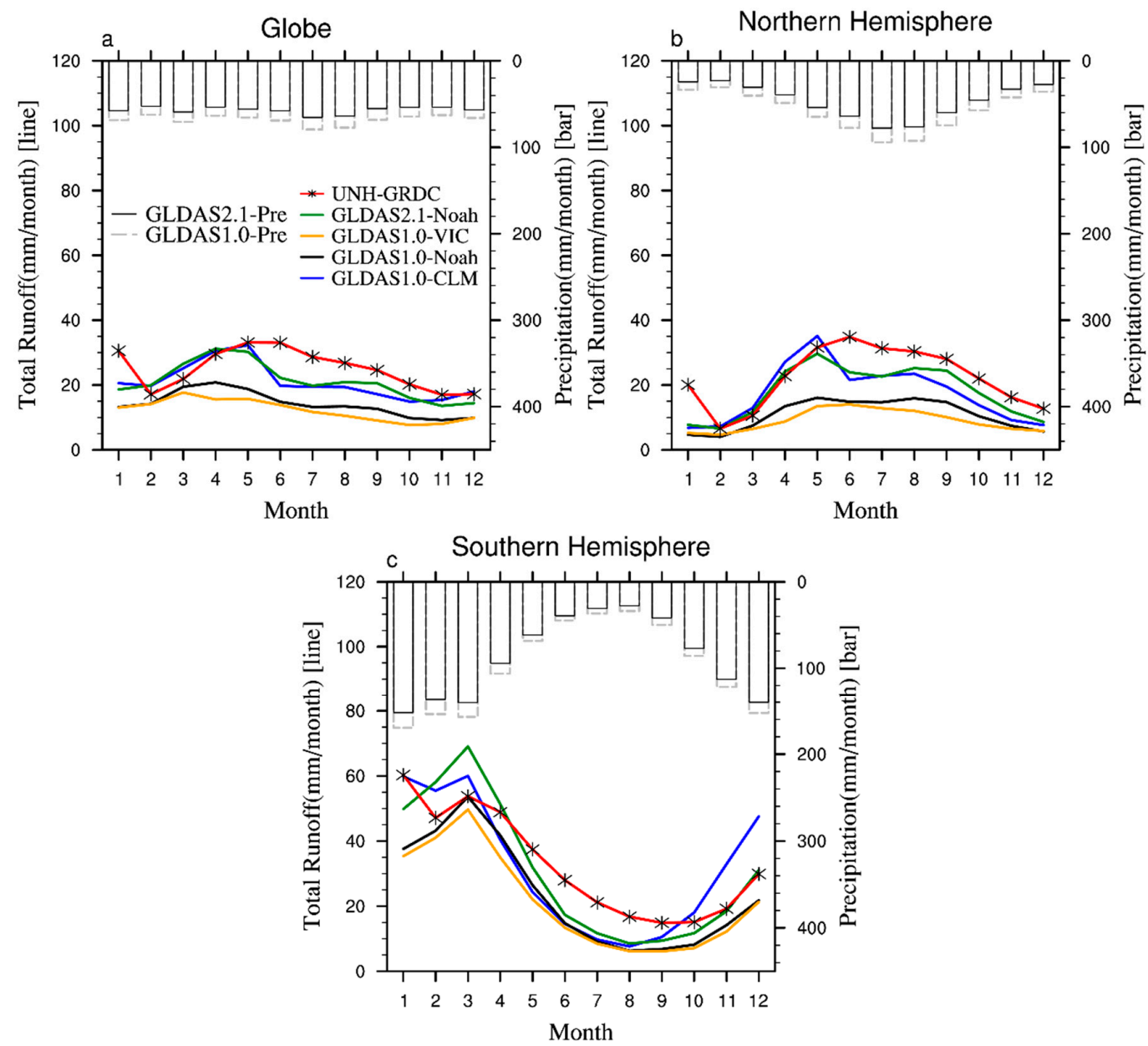

Figure 4. The monthly total runoff averaged over the globe (a), Northern Hemisphere (b), and Southern Hemisphere (c). The dark and gray bars represent precipitation used in GLDAS2.1 and GLDAS1.0, respectively. 
Table 2. RMSE computed by the monthly area-weighted average runoff from each of four GLDAS datasets and UNH-GRDC.

\begin{tabular}{cccc}
\hline Land Surface Model & Globe & Northern Hemisphere & Southern Hemisphere \\
\hline GLDAS1.0-CLM & 6.608 & 7.774 & 10.311 \\
GLDAS1.0-VIC & 13.814 & 14.557 & 12.426 \\
GLDAS1.0-Noah & 11.952 & 12.603 & 10.553 \\
GLDAS2.1-Noah & 6.248 & 6.122 & 8.245 \\
\hline
\end{tabular}

It is noteworthy that, both the GLDAS and UNH-GRDC runoff peak times were not consistent with that of precipitation in the northern hemisphere, which further resulted in the inconsistent peak times for the global scale. Although the main peak time for precipitation was July, the primary runoff peak times in the UNH-GRDC and GLDAS models varied from May to June. Our analysis indicates that, in high-latitude regions, the runoff was greatly associated with snowmelt which usually occurred in late spring and early summer [18]. As shown in Figure 5, peak runoff in the northern, middle, and high latitudes moves northward as the temperature rises from February to June. The UNH-GRDC peak time was in June, despite a slightly higher rainfall-runoff in July between $5^{\circ} \mathrm{N}-40^{\circ} \mathrm{N}$ where the increased precipitation is mainly located. This was due to snowmelt water dominating in June when the UNH-GRDC peak flow event occurred. The temporal and spatial variations of the snow melting phenomenon from GLDAS1.0-VIC matched well with UNH-GRDC, and were in better accordance with temperature changes. However, the start time of snow melting was much earlier in other GLDAS models. For example, they began to produce obvious snowmelt runoff at $50^{\circ} \mathrm{N}$ to $70^{\circ} \mathrm{N}$ from April, and in May simulated considerable snowmelt runoff in the $70^{\circ} \mathrm{N}$ to $80^{\circ} \mathrm{N}$ region where UNH-GRDC showed no snowmelt runoff at all. GLDAS1.0-Noah showed the earliest snowmelt, which was consistent with a recognized tendency that Noah v2.7 often exhibited premature snowmelt in regions with a deep seasonal snowpack $[18,43,44]$. The start time of GLDAS2.1-Noah was somewhat improved (still earlier than the observation), but during June-July GLDAS2.1-Noah displayed excessively high flows which were even higher than the peak over low-latitude areas near the equator.

To further investigate the relationship between the primary peak time and melting snow, we computed the increased runoff relative to the previous month (Figure 6). A positive increase indicates that the runoff in the current month is higher than that in the previous month. In northern, middle and high latitudes, UNH-GRDC runoff started to increase in those latitudes where the temperature rose over $0{ }^{\circ} \mathrm{C}$ during the snowmelt seasons of March to June. However, the runoff in most GLDAS models-i.e., GLDAS2.1-Noah, GLDAS1.0-Noah, and GLDAS1.0-CLM-started to increase before the temperature reached $0{ }^{\circ} \mathrm{C}$. This probably accounts for the earlier runoff in GLDAS models. It should be noted that, different from other GLDAS models, the GLDAS1.0-VIC generated increased runoff when the temperature reached $0{ }^{\circ} \mathrm{C}$, which is generally consistent with the UNH-GRDC data (Figure 6). Consequently, the peak time of runoff in GLDAS1.0-VIC was closer to that in UNH-GRDC than in the other models (Figure 5). 

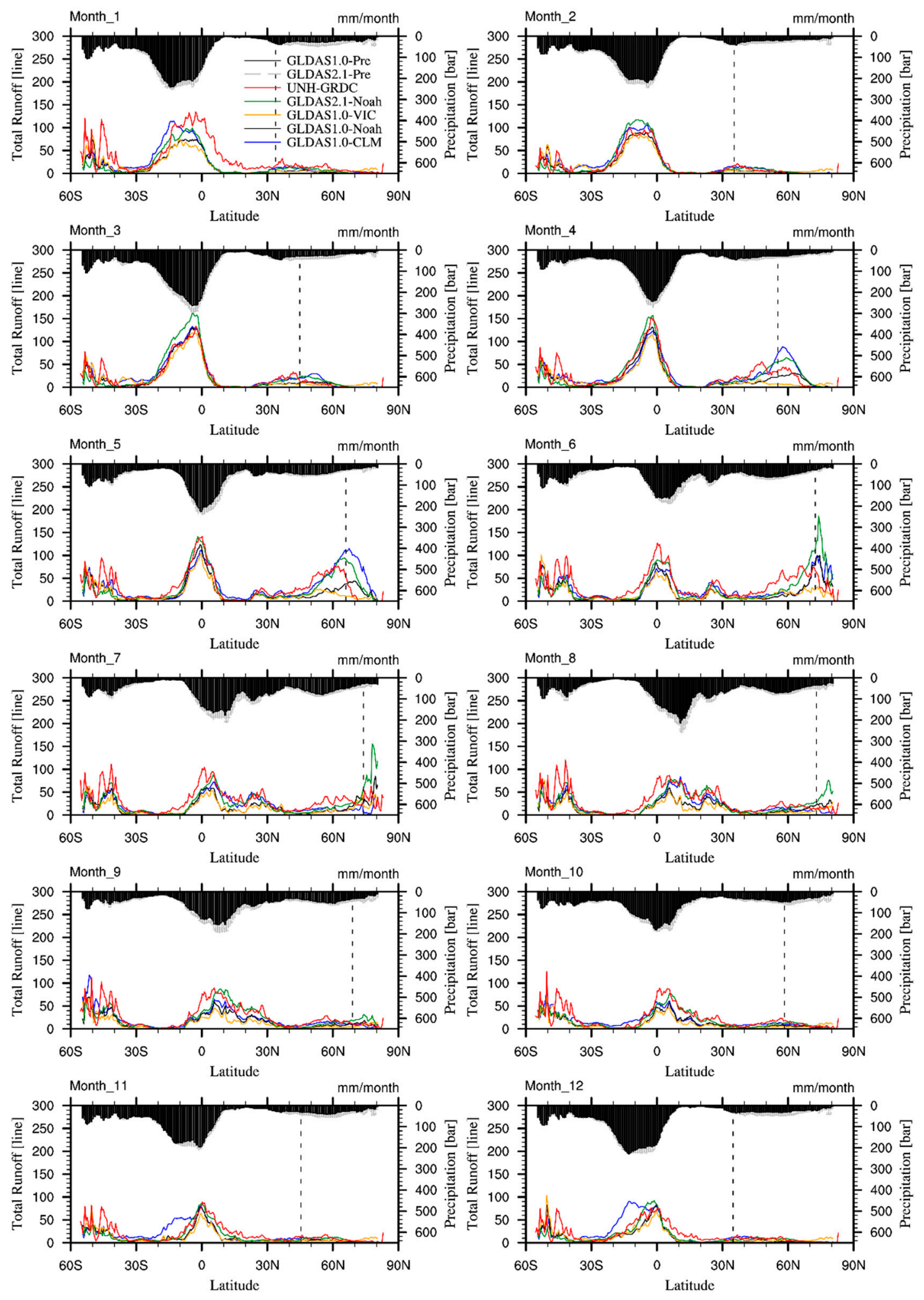

Figure 5. The runoff latitude distributions for GLDAS and UNH-GRDC. The black dashed line represents the location of $0^{\circ} \mathrm{C}$ isotherm which is roughly taken as the melting temperature of snowpack. The latitudinal weight is considered in the computation. 

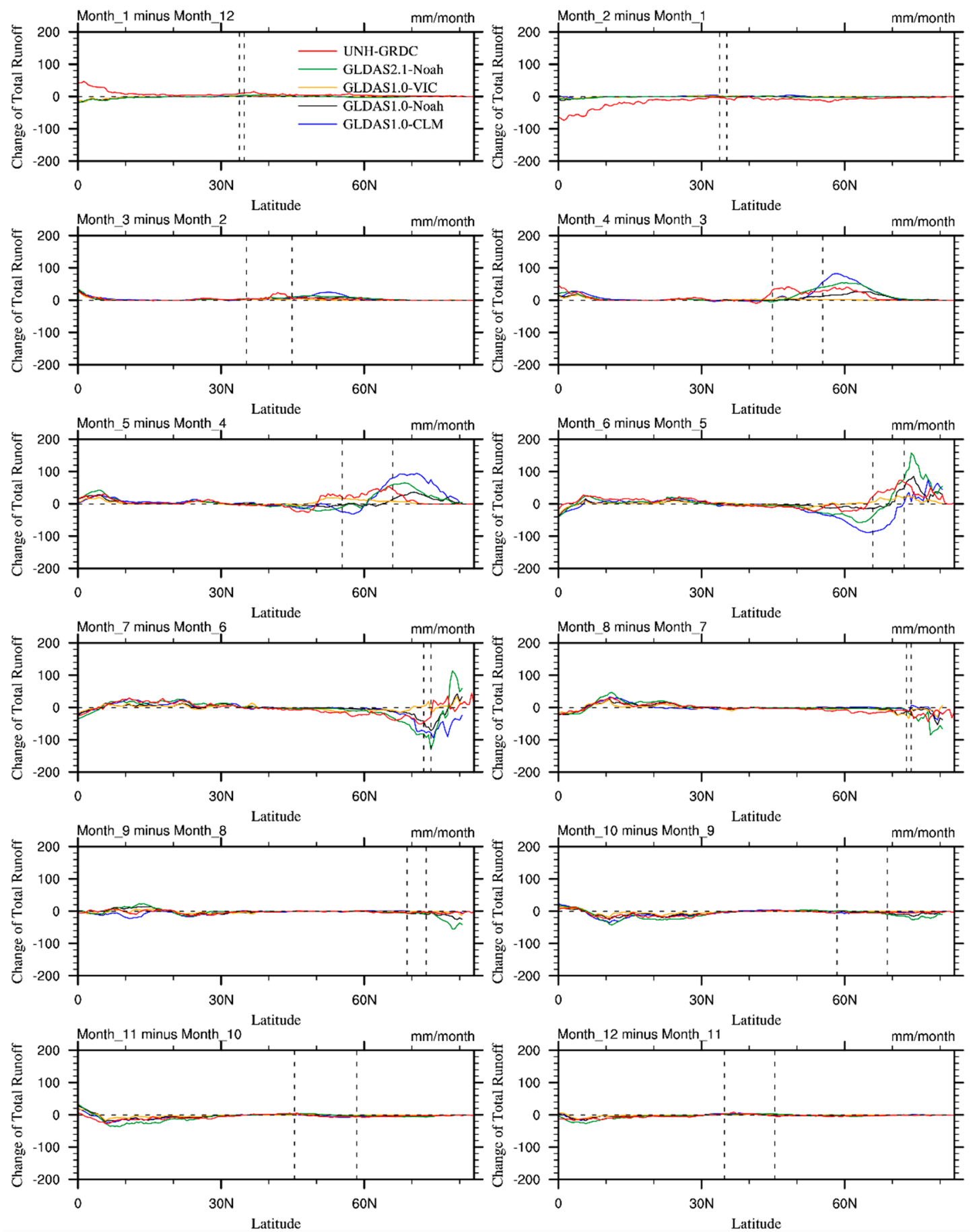

Figure 6. The latitude distributions of monthly runoff change for GLDAS and UNH-GRDC. The black dashed line represents the location of $0{ }^{\circ} \mathrm{C}$ isotherm.

\subsection{Differences in Surface and Subsurface Runoff Components}

The total runoff is composed of surface and subsurface runoffs. Even if the total runoff result is correct, the values of surface and subsurface components may contain compensating errors. Therefore, it is necessary to discuss the partition of total runoff into surface and subsurface runoffs, and to compare their temporal and spatial distributions. This has received less attention in previous studies. Because the UNH-GRDC Composite Runoff Dataset only provides the total runoff results, this hinders our evaluation of GLDAS's surface and subsurface runoffs. Given that there were zero values in the 
surface and subsurface results, the ratio of surface runoff minus subsurface runoff to total runoff was used to discuss the differences between the two components. Through intercomparing the spatial distributions of different runoff components and the ratio of surface runoff minus subsurface runoff to total runoff (Figure 7) as well as the monthly curves for area-weighted average (Figure 8), we found that the component ratio and distribution patterns apparently varied from model to model.

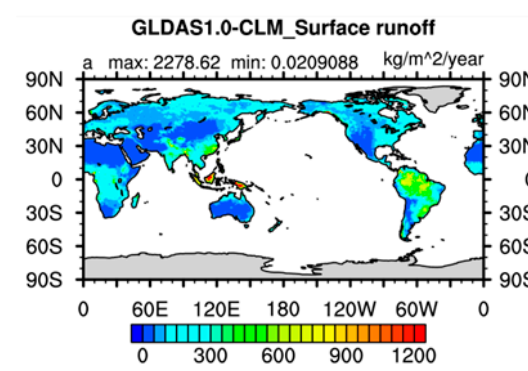

GLDAS1.0-CLM_Subsurface runoff
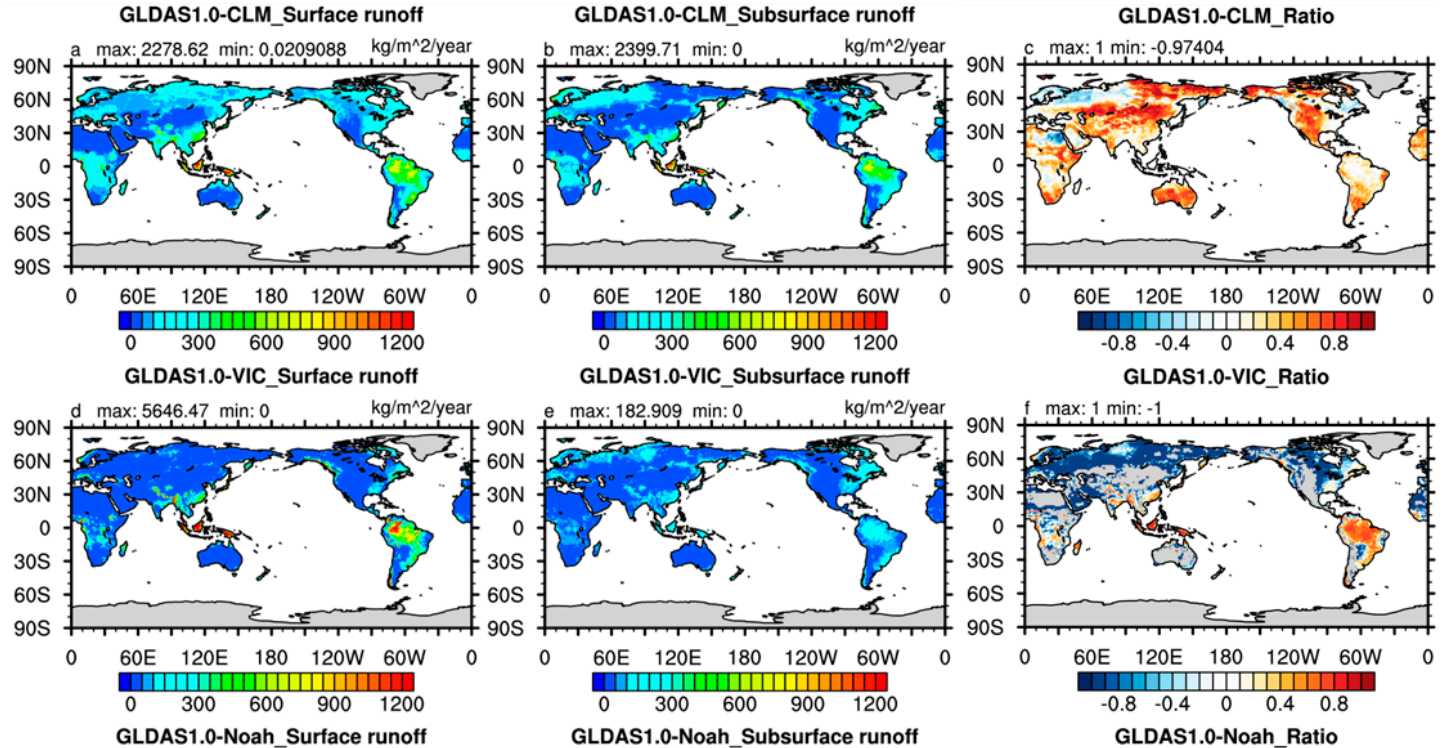

GLDAS1.0-VIC_Subsurface runoff

GLDAS1.0-VIC_Ratio
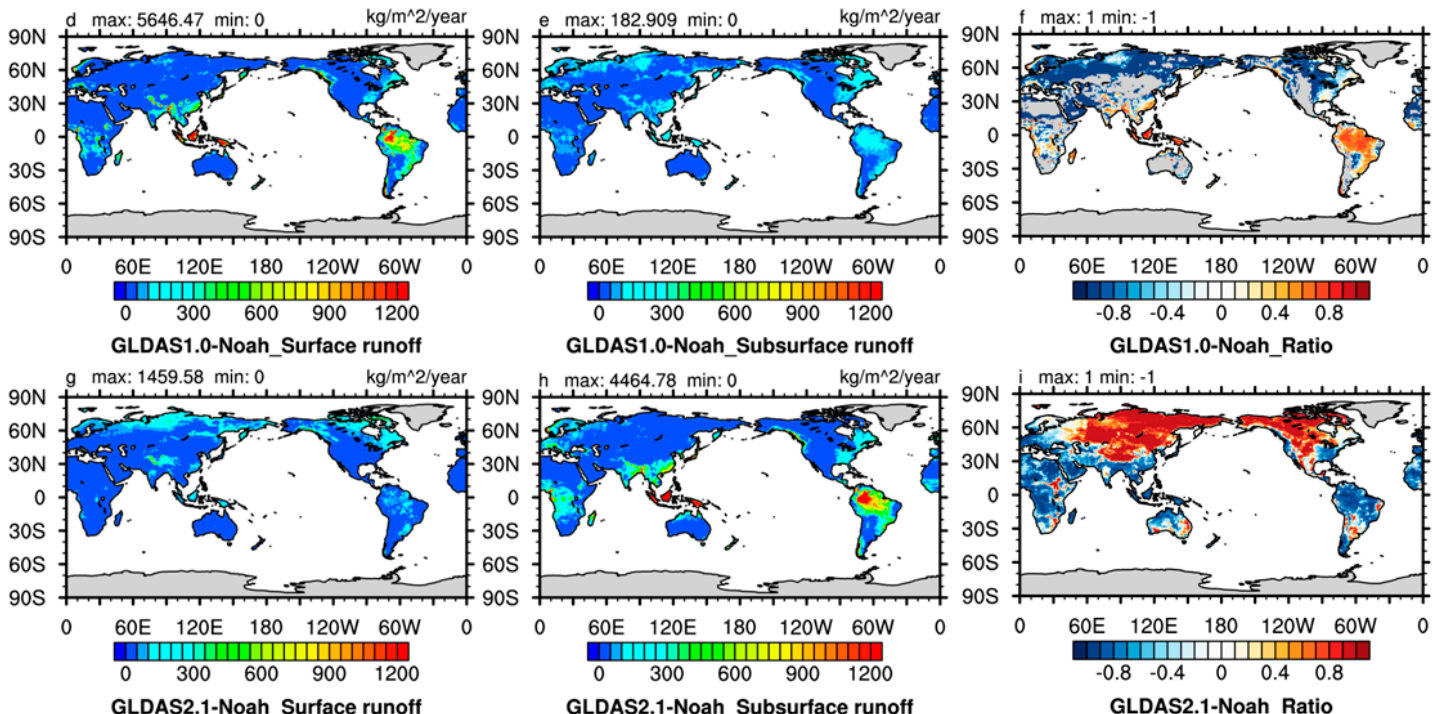

GLDAS1.0-Noah_Subsurface runoff
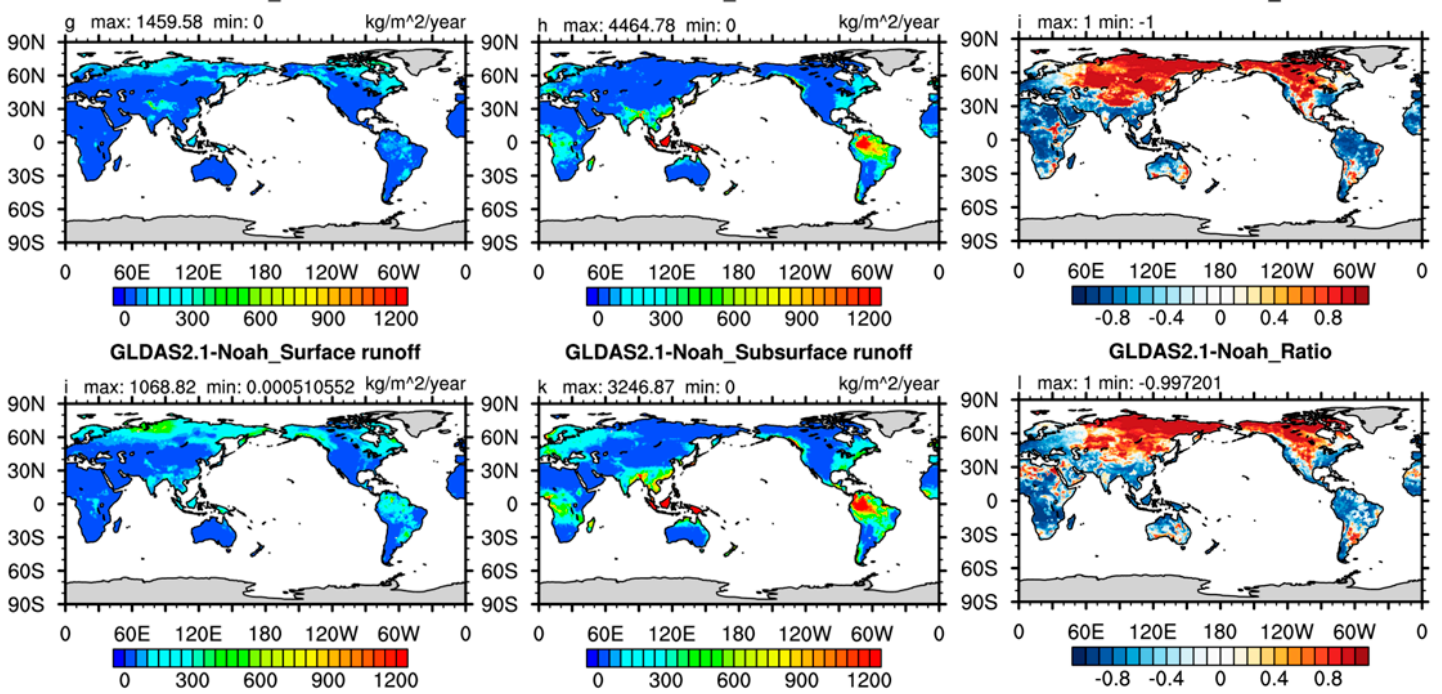

Figure 7. The distributions of surface and subsurface runoff components for GLDAS models and the ratio of surface runoff minus subsurface runoff to total runoff: (surface runoff-subsurface runoff)/total runoff. The gray color shows the total runoff to be zero. 

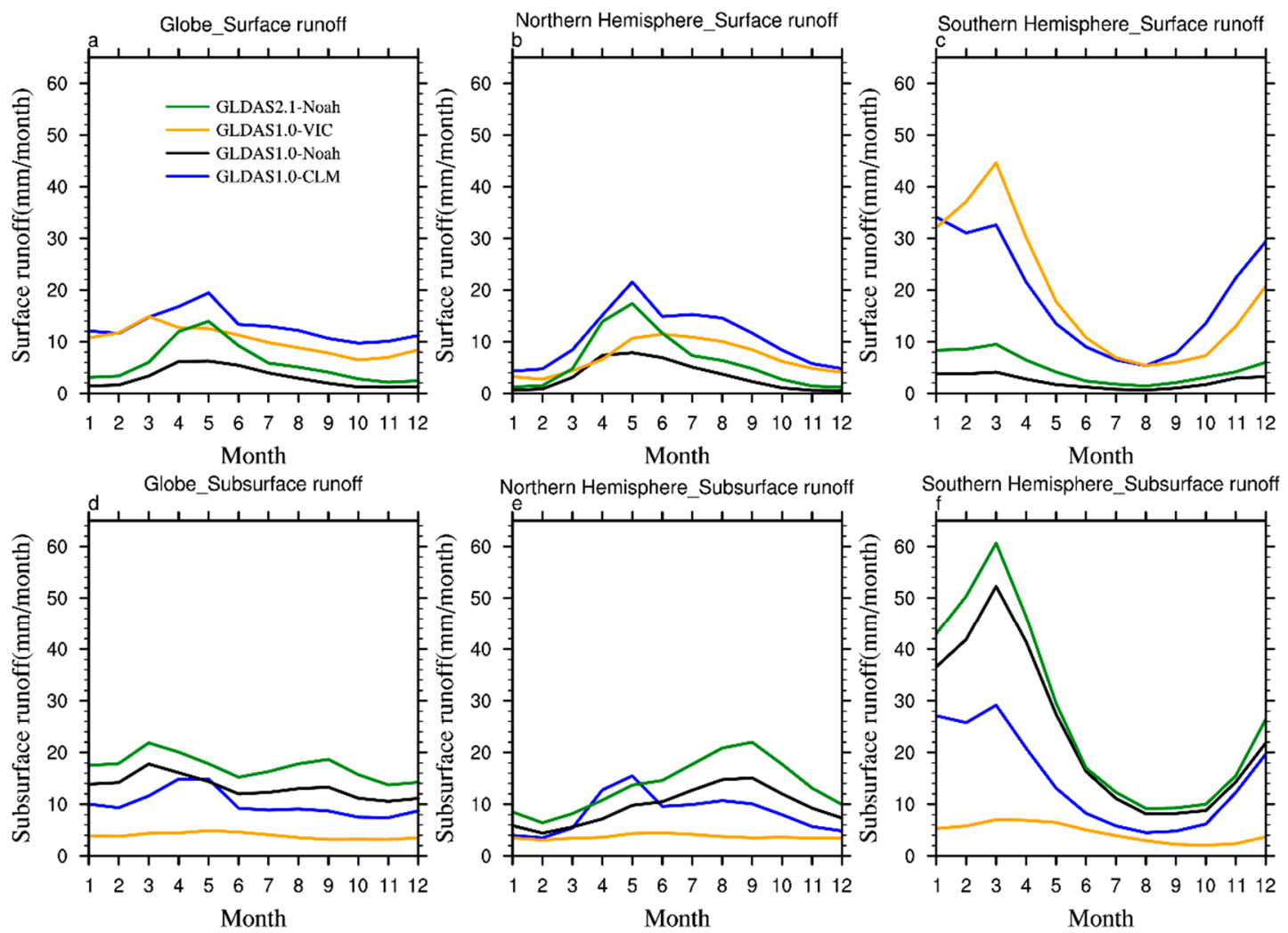

Figure 8. The area-weighted mean of different runoff components on the global and hemispheric scales.

As is generally known, the runoff is mostly generated from low latitude areas between $30^{\circ} \mathrm{S}-30^{\circ} \mathrm{N}$, especially the Amazon River, which is the single, largest source of freshwater on Earth [45]. The differences between surface and subsurface runoffs in GLDAS1.0-CLM were not too large. The two components were basically evenly divided in the primary runoff-produce area where the ratio was close to zero. The surface runoff was a little higher over most of the remaining regions as shown in Figures 7a-c and 8. Their spatial patterns displayed slight regional differences-the subsurface snowmelt runoff mainly located at $0-90^{\circ} \mathrm{E}$, while the surface snowmelt runoff was generated throughout the longitude. In seasonal variations as shown by Figure $8 \mathrm{a}-\mathrm{c}$, these two components were close to each other in curve shape, and the peak times for surface and subsurface processes were exactly the same.

However, it was found that, in GLDAS1.0-VIC, the total runoff over the primary runoff-yield area was dominated by the surface runoff. The subsurface runoff, whose spatial pattern was similar to GLDAS1.0-CLM, was significantly underestimated at the global scale as can be seen in Figure 8d-f. The snowmelt runoff at high latitudes in GLDAS1.0-VIC was made up almost entirely of subsurface runoff, and the difference of subsurface runoff and surface runoff proportions was larger than or equal to $90 \%$. Moreover, the subsurface runoff yielded for each month was relatively stable, thus its monthly variation curve was quite flat. However, GLDAS1.0-Noah and GLDAS2.1-Noah exhibited exactly the opposite spatial distribution characteristics to GLDAS1.0-VIC. This meant that the Noah model produced greater subsurface runoff in the primary runoff-yield areas, and showed dominant surface runoff at middle and high latitudes. The proportional differences for these two situations were all larger than $80 \%$. In particular in the southern hemisphere, the surface runoff was so low that it can almost be ignored. The melting snow runoff basically came from the surface runoff. Meanwhile, we found that Noah had a large disparity in peak times of surface and subsurface runoff. In the northern hemisphere, the surface runoff peak time was May, while the subsurface runoff peaked in 
September. On the global scale, the peak time of surface runoff was also May, but the subsurface runoff curve had two peaks in March and September.

\subsection{Discussion}

The current evaluations of GLDAS runoff were generally limited to the observation-rich areas, though its one strength is to supply data in data-poor regions. In some studies, GLDAS runoff was evaluated indirectly by comparing the GLDAS-driven river routing model simulation with observed streamflow [12,18], which was very likely to introduce uncertainty. Moreover, the partitioning of surface and subsurface runoffs is very important in soil moisture and ET simulations. However, the distribution characteristics of different runoff components for the northern and southern hemispheres have seldom been studied. This study carries out the runoff (total, surface, and subsurface runoffs) assessments at global and hemispheric scales.

The previous evaluations [12,18] showed that among GLDAS1.0 models, GLDAS1.0-VIC was generally quite accurate in estimating the timing of peak discharge globally, and the GLDAS 1.0-Noah model presented the best performance in simulating the seasonal cycle. In this study, GLDAS1.0-VIC only obtained accurate peak time in the northern hemisphere, and the intra-annual variations from GLDAS1.0-CLM were closer to UNH-GRDC than GLDAS1.0-Noah. These differences may be because the earlier intercomparisons were conducted at basin scale using a water routing module.

The uncertainty in this study may come from the UNH-GRDC data. Although the time period of discharge gauging stations used in the GRDC dataset varies station by station, the majority (more than $60 \%$ ) of these stations operated during 1970 to 1980, the UNH-GRDC is still recognized as the best available gridded data for model evaluations [38-41].

\section{Conclusions}

The global land data assimilation system (GLDAS) provides a long-term global distributed runoff, which is highly demanded in water cycle research and water resources management. This study assessed the runoff performance of the prevailing land surface models in GLDAS1.0 and 2.1 versions by intercomparison and validation of the models using the UNH-GRDC global runoff dataset. The results shown in this study reveal the advantages as well as the shortcomings of each GLDAS land surface model in simulating global runoff. These results can benefit both GLDAS data users and land surface model developers.

From view of total runoff simulation, GLDAS1.0-VIC and GLDAS1.0-Noah markedly underestimated the total runoff, while the results from GLDAS1.0-CLM and GLDAS2.1-Noah were relatively close to UNH-GRDC observations. All of the GLDAS models underestimated the runoff in the north of South America and south-southeast Asia. GLDAS2.1-Noah performed best in terms of statistical metrics in total runoff simulation. Meanwhile, UNH-GRDC and GLDAS models exhibited different area-weighted averaged runoff patterns. In the northern hemisphere, the primary peak times in both GLDAS and UNH-GRDC did not match with the precipitation. Although the precipitation peak occurred in July, the primary runoff peak times from the UNH-GRDC and GLDAS models varied from May to June. This was because the peak flow was caused by a combination of rainfall and melting snow over high-latitude areas rather than by the rainfall itself, hence the peak flow presented in the month when the accumulation of rainfall-runoff and snowmelt-runoff reached the maximum. Moreover, GLDAS1.0-CLM, GLDAS2.1-Noah, and especially GLDAS1.0-Noah presented the premature snow melt. It is noted that GLDAS2.1-Noah improved the premature snow-melting tendency in GLDAS1.0-Noah, but showed excessively high peak flows in June and July. GLDAS1.0-VIC simulated the reasonable time-space distribution, but severely underestimated the snowmelt runoff.

In terms of runoff components, significant disparities existed in different runoff components' ratios, spatial patterns, and peak times among GLDAS models. The proportions of surface and subsurface runoffs in GLDAS1.0-CLM were basically evenly partitioned in the primary runoff-produce area, but with moderately higher surface runoff over most of the rest of the regions. Meanwhile, the two 
components in GLDAS1.0-CLM exhibited similar spatial patterns. For GLDAS1.0-VIC, the total runoff over the primary runoff-yield area was mainly composed of the surface runoff, but the snowmelt runoff at northern high latitudes came mostly from the subsurface runoff. The Noah from both GLDAS1.0 and 2.1 versions showed the opposite patterns to GLDAS1.0-VIC. Furthermore, the peak times of surface and subsurface runoff in GLDAS1.0-CLM and GLDAS1.0-VIC were basically the same, but the results in GLDAS1.0-Noah and GLDAS2.1-Noah showed a big difference.

These conclusions show that when using the GLDAS data, the disparities in partition of surface and subsurface runoff, in snowmelt runoff modeling, and in capturing the peak time in the northern hemisphere, cannot be neglected. In future work, the improvement of hydrological parameterized schemes will still be an important issue, in which adopting the available observed data (e.g., UNH-GRDC) in calibration as well as validation is very much needed.

Author Contributions: H.L., K.Y., and M.L. conceived and designed the study; M.L., Z.X., M.L., and X.H. conducted the comparison and analyzed the results; M.L. wrote the paper and all of the authors contributed to the paper writing.

Funding: This work was funded by the National Key Research and Development Program of China (2017YFA0603703 \& 2016YFB0201100) and the National Natural Science Foundation of China (91537210, 91747101, 91637103, \& 41675080).

Acknowledgments: We wish to thank Arthur Cracknell and Pauline Lovell for revising the paper. The GLDAS data used in this study were acquired as part of the mission of NASA's Earth Science Division and archived and distributed by the Goddard Earth Sciences (GES) Data and Information Services Center (DISC).

Conflicts of Interest: The authors declare no conflict of interest.

\section{References}

1. Mahmood, R.; Keeling, T.; Foster, S.A.; Hubbard, K.G. Did irrigation impact 20th century temperature in the High Plains aquifer region? Appl. Geogr. 2013, 38, 11-21. [CrossRef]

2. Seneviratne, S.I.; Corti, T.; Davin, E.L.; Hirschi, M.; Jaeger, E.B.; Lehner, I.; Orlowsky, B.; Teuling, A.J. Investigating soil moisture-climate interactions in a changing climate: A review. Earth Sci. Rev. 2010, 99, 125-161. [CrossRef]

3. Wei, J.; Dirmeyer, P.A. Toward understanding the large-scale land-atmosphere coupling in the models: Roles of different processes. Geophys. Res. Lett. 2010, 37, 351-369. [CrossRef]

4. Yeh, T.; Wetherald, R.T.; Manabe, S. The effect of soil moisture on the short-term climate and hydrology change-A numerical experiment. Mon. Weather. Rev. 1984, 112, 474-490. [CrossRef]

5. Kuhl, S.C.; Miller, J.R. Seasonal river runoff calculated from a global atmospheric model. Water Resour. Res. 1992, 28, 2029-2039. [CrossRef]

6. Crossley, J.F.; Polcher, J.; Cox, P.M.; Gedney, N.; Planton, S. Uncertainties linked to land-surface processes in climate change simulations. Clim. Dyn. 2000, 16, 949-961. [CrossRef]

7. Dan, L.; Ji, J.; Li, Y. Climatic and biological simulations in a two-way coupled atmosphere-biosphere model (CABM). Glob. Planet. Chang. 2005, 47, 153-169. [CrossRef]

8. Pitman, A.J. The evolution of, and revolution in, land surface schemes designed for climate models. Int. J. Climatol. 2010, 23, 479-510. [CrossRef]

9. Zabel, F. Land-Atmosphere Coupling between A Land Surface Hydrological Model and A RegionalClimate Model. Ph.D. Thesis, Ludwig-Maximilians-Universität München, München, Germany, 21 June 2012.

10. Kumar, S.V.; Peters-Lidard, C.D.; Tian, Y.; Houser, P.R.; Geiger, J.; Olden, S.; Lighty, L.; Eastman, J.L.; Doty, B.; Dirmeyer, P. Land information system: An interoperable framework for high resolution land surface modeling. Environ. Modell. Softw. 2006, 21, 1402-1415. [CrossRef]

11. Rodell, M.; Houser, P.R.; Jambor, U.; Gottschalck, J.; Mitchell, K.; Meng, C.-J.; Arsenault, K.; Cosgrove, B.; Radakovich, J.; Bosilovich, M.; et al. The global land data assimilation system. Bull. Am. Meteorol. Soc. 2004, 85, 381-394. [CrossRef]

12. Bai, P.; Liu, X.; Yang, T.; Liang, K.; Liu, C. Evaluation of streamflow simulation results of land surface models in GLDAS on the Tibetan Plateau. J. Geophys. Res. Atmos. 2016, 121, 12180-12197. [CrossRef] 
13. Khan, M.S.; Liaqat, U.W.; Baik, J.; Choi, M. Stand-alone uncertainty characterization of GLEAM, GLDAS and MOD16 evapotranspiration products using an extended triple collocation approach. Agric. For. Meteorol. 2018, 252, 256-268. [CrossRef]

14. Kim, H.; Parinussa, R.; Konings, A.G.; Wagner, W.; Cosh, M.H.; Lakshmi, V.; Zohaib, M.; Choi, M. Global-scale assessment and combination of SMAP with ASCAT (active) and AMSR2 (passive) soil moisture products. Remote. Sens. Environ. 2018, 204, 260-275. [CrossRef]

15. Syed, T.H.; Famiglietti, J.S.; Rodell, M.; Chen, J.; Wilson, C.R. Analysis of terrestrial water storage changes from GRACE and GLDAS. Water Resour. Res. 2008, 44, W02433. [CrossRef]

16. Wang, W.; Cui, W.; Wang, X.; Chen, X. Evaluation of GLDAS-1 and GLDAS-2 forcing data and Noah model simulations over China at monthly scale. J. Hydrometeorol. 2016, 17, 2815-2833. [CrossRef]

17. Xiao, R.; He, X.; Zhang, Y.; Ferreira, V.G.; Chang, L. Monitoring groundwater variations from satellite gravimetry and hydrological models: A comparison with in-situ measurements in the Mid-Atlantic region of the United States. Remote. Sens. 2015, 7, 686-703. [CrossRef]

18. Zaitchik, B.F.; Rodell, M.; Olivera, F. Evaluation of the global land data assimilation system using global river discharge data and a source-to-sink routing scheme. Water Resour. Res. 2010, 46, 2840-2849. [CrossRef]

19. Zhang, J.; Wang, W.C.; Wei, J. Assessing land-atmosphere coupling using soil moisture from the Global Land Data Assimilation System and observational precipitation. J. Geophys. Res. Atmos. 2008, 113, D17119. [CrossRef]

20. Koster, R.D.; Suarez, M.J.; Liu, P.; Jambor, U.; Berg, A.; Kistler, M.; Reichle, R.; Rodell, M.; Famiglietti, J. Realistic initialization of land surface states: Impacts on subseasonal forecast skill. J. Hydrometeorol. 2004, 5, 1049-1063. [CrossRef]

21. Ye, K.; Lau, N.C. Characteristics of eurasian snowmelt and its impacts on the land surface and surface climate. Clim. Dyn. 2018. [CrossRef]

22. Spennemann, P.; Rivera, J.A.; Osman, M.; Saulo, C.; Penalba, O. Assessment of seasonal soil moisture forecasts over southern South America with emphasis on dry and wet events. In Proceedings of the EGU General Assembly Conference, Vienna, Austria, 23-28 April 2017.

23. Spennemann, P.C.; Rivera, J.A.; Saulo, A.C.; Penalba, O.C. A comparison of GLDAS soil moisture anomalies against standardized precipitation index and multisatellite estimations over South America. J. Hydrometeorol. 2015, 16, 158-171. [CrossRef]

24. Chen, Y.; Yang, K.; Qin, J.; Zhao, L.; Tang, W.; Han, M. Evaluation of AMSR-E retrievals and GLDAS simulations against observations of a soil moisture network on the central Tibetan Plateau. J. Geophys. Res. Atmos. 2013, 118, 4466-4475. [CrossRef]

25. Mo, X.; Wu, J.J.; Wang, Q.; Zhou, H. Variations in water storage in China over recent decades from GRACE observations and GLDAS. Nat. Hazards Earth Syst. Sci. 2016, 3, 3251-3286. [CrossRef]

26. Ji, L.; Senay, G.B.; Verdin, J.P. Evaluation of the global land data assimilation system (GLDAS) air temperature data products. J. Hydrometeorol. 2015, 16, 2463-2480. [CrossRef]

27. Kato, H.; Rodell, M.; Beyrich, F.; Cleugh, H.; van Gorsel, E.; Liu, H.; Meyers, T.P. Sensitivity of land surface simulations to model physics, land characteristics, and forcings, at four CEOP sites. J. Meteorol. Soc. Jpn. 2007, 85A, 187-204. [CrossRef]

28. Jiménez, C.; Prigent, C.; Mueller, B.; Seneviratne, S.I.; Mccabe, M.F.; Wood, E.F.; Rossow, W.B.; Balsamo, G.; Betts, A.K.; Dirmeyer, P.A. Global intercomparison of 12 land surface heat flux estimates. J. Geophys. Res. Atmos. 2011, 116, 3-25. [CrossRef]

29. Ferguson, C.R.; Wood, E.F.; Vinukollu, R.K. A global intercomparison of modeled and observed land-atmosphere coupling. J. Hydrometeorol. 2012, 13, 749-784. [CrossRef]

30. Rui, H.; Beaudoing, H. README Document for Global Land Data Assimilation System Version 2 (GLDAS-2) Products; Goddard Space Flight Center: Greenbelt, MD, USA, 2017.

31. Derber, J.C.; Parrish, D.F.; Lord, S.J. The new global operational analysis system at the National Meteorological Center. Weather Forecast. 1991, 6, 538-547. [CrossRef]

32. Adler, R.F.; Huffman, G.J.; Chang, A.; Ferraro, R.; Xie, P.-P.; Janowiak, J.; Rudolf, B.; Schneider, U.; Curtis, S.; Bolvin, D.; et al. The version-2 global precipitation climatology project (GPCP) monthly precipitation analysis (1979-present). J. Hydrometeorol. 2003, 4, 1147-1167. [CrossRef]

33. Bonan, G.B. The land surface climatology of the NCAR Land Surface Model coupled to the NCAR Community Climate Model. J. Clim. 1998, 11, 1307-1326. [CrossRef] 
34. Dickinson, R.E.; Henderson-Sellers, A.; Kennedy, P.J.; Wilson, M.F. Biosphere-atmosphere Transfer Scheme (BATS) NCAR Community Climate Model; National Technicalt Information Service: Alexandria, VA, USA, 1986.

35. Dai, Y.; Zeng, Q. A land surface model (IAP94) for climate studies part I: Formulation and validation in off-line experiments. Advances Atmos.Sci. 1997, 14, 433-460.

36. Zhao, R.-J. The Xinanjiang model applied in China. J. Hydrol. 1992, 135, 371-381.

37. Zhou, X.; Zhang, Y.; Yang, Y.; Han, S. Evaluation of anomalies in GLDAS-1996 dataset. Water Sci. Technol. 2013, 67, 1718-1727. [CrossRef] [PubMed]

38. Cai, X.; Yang, Z.L.; David, C.H.; Niu, G.Y.; Rodell, M. Hydrological evaluation of the Noah-MP land surface model for the Mississippi River Basin. J. Geophys. Res. Atmos. 2015, 119, 23-38. [CrossRef]

39. Du, E.; Vittorio, A.D.; Collins, W.D. Evaluation of hydrologic components of community land model 4 and bias identification. Int. J. Appl. Earth Obs. Geoinf. 2016, 48, 5-16. [CrossRef]

40. Fekete, B.M.; Voeroesmarty, C.J.; Grabs, W. Global Composite Runoff Fields Based on Observed River Discharge and Simulated Water Balances; Global Runoff Data Centre (GRDC); Federal Institute of Hydrology (BfG): Koblenz, Germany, February 2000.

41. Fekete, B.M.; Vörösmarty, C.J.; Grabs, W. High-resolution fields of global runoff combining observed river discharge and simulated water balances. Glob. Biogeochem. Cycles 2002, 16, 15-1-15-10. [CrossRef]

42. Taylor, K.E. Summarizing multiple aspects of model performance in a single diagram. J. Geophys. Res. Atmos. 2001, 106, 7183-7192. [CrossRef]

43. Sheffield, J.; Pan, M.; Wood, E.F.; Mitchell, K.E.; Houser, P.R.; Schaake, J.C.; Robock, A.; Lohmann, D.; Cosgrove, B.; Duan, Q. Snow process modeling in the north american land data assimilation system (NLDAS): 1. Evaluation of model-simulated snow cover extent. J. Geophys. Res. Atmos. 2003, 108, 2101-2110. [CrossRef]

44. Zaitchik, B.F.; Rodell, M. Forward-looking assimilation of MODIS-derived snow-covered area into a land surface model. J. Hydrometeorol. 2009, 10, 130-148. [CrossRef]

45. Marengo, J.A. On the hydrological cycle of the amazon basin: A historical review and current state-of-the-art. Rev. Bras. Meteorol. 2006, 21, 1-19. 